\title{
Risks of adverse pregnancy and birth outcomes in women treated or not treated with mood stabilisers for bipolar disorder: population based cohort study
}

\author{
(9) (1) $\Theta$ OPEN ACCESS
}

\author{
Robert Bodén consultant psychiatrist and researcher ${ }^{12}$, Maria Lundgren paediatrician and \\ researcher ${ }^{3}$, Lena Brandt biostatistician and epidemiologist ${ }^{2}$, Johan Reutfors consultant psychiatrist \\ and researcher ${ }^{2}$, Morten Andersen clinical pharmacologist and visiting professor ${ }^{2}$, Helle Kieler \\ associate professor in obstetrics and gynaecology and head ${ }^{2}$
}

${ }^{1}$ Department of Neuroscience, Psychiatry, Uppsala University, Ing 15 3tr, SE-751 85 Uppsala, Sweden ; ${ }^{2}$ Centre for Pharmacoepidemiology, Department of Medicine Solna, Karolinska Institutet, Sweden; ${ }^{3}$ Department of Women's and Children's Health, Uppsala University, Uppsala, Sweden

\begin{abstract}
Objective To investigate the risks of adverse pregnancy and birth outcomes for treated and untreated bipolar disorder during pregnancy.

Design Population based cohort study using data from national health registers.

\section{Setting Sweden.}

Participants 332137 women with a last menstrual period anytime after 1 July 2005 and giving birth anytime before the end of 31 December 2009. Women with a record of at least two bipolar diagnoses were identified and grouped as treated $(n=320)$ - those who had filled a prescription for mood stabilisers (lithium, antipsychotics, or anticonvulsants) during pregnancy-or untreated $(n=554)$. Both groups were compared with all other women giving birth $(n=331263)$.

Main outcome measures Preterm birth, mode of labour initiation, gestational diabetes, infants born small or large for gestational age, neonatal morbidity, and congenital malformations.
\end{abstract}

Results Of the untreated women, $30.9 \%(n=171)$ were induced or had a planned caesarean delivery compared with $20.7 \%(n=68533)$ without bipolar disorder (odds ratio $1.57,95 \%$ confidence interval 1.30 to 1.90 ). The corresponding values for the treated women were $37.5 \%(n=120)$ $(2.12,1.68$ to 2.67$)$. The risks of preterm birth in both treated and untreated women were increased by $50 \%$. Of the untreated women, $3.9 \%(n=542)$ had a microcephalic infant compared with $2.3 \%$ (324 844) of the women without bipolar disorder $(1.68,1.07$ to 2.62$)$. The corresponding values for the treated women were $3.3 \%(n=311)(1.26$, 0.67 to 2.37). Similar trends were observed for risks of infants being small for gestational age infants for weight and length. Among infants of untreated women, $4.3 \%(n=24)$ had neonatal hypoglycaemia compared with $2.5 \%(n=8302)$ among infants of women without bipolar disorder $(1.51,1.04$ to 2.43$)$, and $3.4 \%(n=11)$ of the treated women $(1.18,0.64$ to 2.16). The analyses of variation in outcomes did not support any significant differences between treated and untreated women.

Conclusions Bipolar disorder in women during pregnancy, whether treated or not, was associated with increased risks of adverse pregnancy outcomes.

\section{Introduction}

Bipolar disorder is a chronic and episodic severe mental disorder, often requiring continuous mood stabilising treatment to prevent relapses and to lower the risk of suicide. ${ }^{2}$ Lithium, certain anticonvulsants, and antipsychotics are recommended as mood stabilisers in bipolar disorder. ${ }^{2}$ Knowledge about the consequences of treatment with mood stabilisers during pregnancy is, however, limited. ${ }^{23}$

Antipsychotics during pregnancy have been associated with congenital malformations, preterm birth, and abnormal fetal growth..$^{4-7}$ In a recent study, however, we could not confirm an association between antipsychotics during pregnancy and abnormal fetal growth, except for an increased risk of macrocephaly after use of clozapine or olanzapine. ${ }^{8}$ Furthermore, antipsychotics, regardless of type, were associated with increased risks of gestational diabetes. ${ }^{8}$ Lithium, valproate, and carbamazepine have been associated with congenital malformations, but for lithium the data are conflicting and difficult to interpret. ${ }^{9-11}$ Some authors suggest lithium as the first line treatment of choice for bipolar disorder during pregnancy, ${ }^{12}$ whereas others have recommended avoiding this drug. ${ }^{10}$

Having a bipolar disorder has been linked to slightly increased risks of pregnancy complications, ${ }^{13}$ preterm birth, and giving birth to small for gestational age infants. ${ }^{14}$ However, previous studies did not assess drug treatment and to our knowledge no 
attempts have been made to differentiate between the influences on potential adverse effects of the illness itself, use of drugs, associated adverse lifestyle behaviours, and comorbidity. We therefore explored the risks of adverse pregnancy and birth outcomes in treated and untreated women with bipolar disorder.

\section{Methods}

We obtained data for this cohort study from three Swedish nationwide registers maintained by the National Board of Health and Welfare: the Swedish prescribed drug register, the medical birth register, and the national patient register. Data from the drug and birth registers included the period from 2005 to 2009, whereas data from the patient register included information from 1997 to 2009. The unique personal identification number assigned to all Swedish permanent residents allows for linkage of information across the three registers. ${ }^{15}$

The Swedish prescribed drug register contains information on all prescriptions filled in Sweden, including the Anatomical Therapeutic Chemical code of dispensed substances, amount, formulation, and date of prescribing and dispensing. ${ }^{16}$ It does not, however, cover drugs administered in hospitals. The medical birth register contains data on almost all births in Sweden. ${ }^{17}$ The information is obtained by midwives and attending doctors in connection with visits and admissions to hospital from the antenatal visit to the neonatal period. The data include maternal personal variables, tobacco use, height and weight in early pregnancy, complications during pregnancy, delivery, and data from the neonatal period (for example, Apgar score and neonatal hypoglycaemia). Furthermore, anthropometrics of the infants (birth weight, birth length, and head circumference) are recorded in the register. The initial visit for antenatal care occurs during the first trimester in more than $95 \%$ of the pregnancies. ${ }^{18}$ Gestational age is primarily based on prenatal ultrasound estimation of the last menstrual period, if present; otherwise it is estimated on the recorded date of the first day of the last menstrual period. Since 1990 ultrasonography for determination of gestational length has been offered to all pregnant women in Sweden (accepted by $95 \%$ ). ${ }^{19}$ The national patient register comprises information on diagnoses from all specialised inpatient and outpatient care in Sweden (excluding primary care facilities with general practitioners). Patients with bipolar disorder are treated within specialised psychiatric care facilities in Sweden, and all information from these facilities is included in the national patient register. Since 1997 the diagnoses have been coded according to the International Classification of Diseases, 10th revision (ICD-10). From the medical birth register we identified women who had an estimated last menstrual period anytime after 1 July 2005 and gave birth to a singleton anytime before the end of 31 December 2009. We excluded those with missing data on smoking, height, or cohabitation, as well as those giving birth to a stillborn infant.

Only women with at least two recorded diagnoses for bipolar disorder (ICD-10 code F30-31) in the national patient register were classified as having bipolar disorder. We defined use of a mood stabiliser as filling a prescription that supplied a quantity of the drug to cover intake during pregnancy according to the prescribed dosage. We assumed that the patient started taking the drug directly after the prescription was filled and followed the dosage directions. Mood stabilisers included lithium, antipsychotic drugs (ATC code N05A, except for prochlorperazine, levomepromazine, and melperone), and any of the anticonvulsants carbamazepine, lamotrigine, and valproate (ATC codes N03AF01, N03AX09, and N03AG01). Women who used mood stabilisers but had no record of a bipolar disorder were excluded from the analyses. We also obtained information about the number of women admitted to a psychiatric hospital during pregnancy and with no prescription filled for antipsychotics. Women with bipolar disorder were classified by use of mood stabilisers as either treated or untreated. The comparison (reference) group consisted of women without a bipolar disorder and their infants.

For congenital malformations, we considered only major ones. Thus we did not include accessory auricle, prominent ear, single umbilical artery, tongue tie, undescended testicle, unstable hip or dislocation/subluxation of the hip joint, polydactyly, syndactyly, or non-neoplastic nevus. We defined instrumental delivery as caesarean delivery or use of forceps or ventouse; gestational diabetes was defined as a recorded diagnosis (ICD code $\mathrm{O} 24$ ) during pregnancy; preterm birth was defined as being born before 37 weeks of gestation; and very preterm was defined as being born before 32 weeks of gestation. Being small for gestational age or large for gestational age on weight, length, and head circumference were defined as a measurement in the $\leq 2.3$ centile or $\geq 97.7$ centile (which corresponds to 2 standard deviations), respectively, of the total population by infant's sex. ${ }^{2021}$ A symmetrical small for gestational age infant was defined as being small for gestational age on both weight and length. Apgar scoring is done by midwives and is an assessment of the newborn infant's heart rate, respiration, muscle tone, and reflex irritability on a scale from $0-10$ points. A low Apgar score at five minutes postpartum was defined as a score of $<7$. Neonatal morbidity included jaundice (ICD-10 codes P57.8, P57.9, P58, and P59) and hypoglycaemia (ICD-10 code P70, except for P70.2).

Potential confounders were maternal country of origin, smoking, height, and cohabitation status at the first antenatal visit, together with maternal age when giving birth, birth order of the infant, and a diagnosis of maternal alcohol or other substance misuse disorder.

\section{Statistical methods}

We compared women with bipolar disorder, either treated or not treated with mood stabilisers during pregnancy, as separate categories with the rest of the study population. All outcomes were analysed using univariate logistic regression models, except for congenital malformations in which we carried out Fisher's exact test because of the low number of events. For the adverse pregnancy and birth outcomes as well as for the anthropometric outcomes, we carried out multivariable analyses after adjusting for the potential confounders of maternal age, height, country of origin, cohabitation, smoking, infants' birth order, and a diagnosis of maternal alcohol or substance misuse disorder. When assessing the Apgar score, we included mode of delivery in the model. To adjust for the effect of more than one child of the same mother, we calculated estimates in all logistic regression models by the generalised estimating equation approach using the GENMOD procedure in SAS software, version 9.2. An overall analysis of the variation in outcome between the three usage groups was done by computing a $\mathrm{P}$ value for each analysis. Estimated risks are presented as odds ratios with $95 \%$ confidence intervals.

\section{Results}

Overall, 332137 women with an estimated last menstrual period anytime after 1 July 2005 and who gave birth to a singleton before the end of 31 December 2009 were identified from the medical birth register (figure $\Downarrow$ ). Women with bipolar disorder, whether treated or not, were more often smokers, overweight, 
and misused alcohol or substances than women without bipolar disorder (table $1 \Downarrow)$. In the treated mothers, $128(40 \%)$ had used lamotrigine during pregnancy. Corresponding figures for lithium and antipsychotic drugs were $127(40 \%)$ and $124(39 \%)$, respectively. Valproate had been used by $37(12 \%)$ women, carbamazepine by 7 (2\%), and lithium by $76(24 \%)$. Seventy one $(9 \%)$ of the women with bipolar disorder had multiple pregnancies during the study period. The corresponding rate for all mothers was $13 \%$.

\section{Pregnancy and birth outcomes}

Table $2 \Downarrow$ shows the pregnancy and birth outcomes. Both untreated and treated women with bipolar disorder had increased risks of caesarean delivery, instrumental delivery, a non-spontaneous start to delivery, and preterm delivery. Among infants of untreated women the risk of being born very preterm was not significantly increased (unadjusted odds ratio $1.96,95 \%$ confidence interval 0.93 to 4.14 ). The corresponding odds ratio for the treated women was 0.48 (0.07 to 3.38). In the analysis of variation in very preterm deliveries between the three usage groups no significant differences were found $(\mathrm{P}=0.15)$. Untreated bipolar disorder was associated with giving birth to an infant with a low Apgar score, but in the multivariate model the increased risk was attenuated and not statistically significant. Infants of the treated women had no increased risks of a low Apgar score. The risk of neonatal hypoglycaemia was increased in the infants of untreated women. The risks of hypoglycaemia in the infants of treated women were also increased, but the risk estimates were imprecise. Neither untreated nor treated bipolar disorder was associated with neonatal jaundice (data not shown).

\section{Small for gestational age}

Table $3 \Downarrow$ lists the anthropometric measures. Untreated bipolar disorder was associated with increased risks of women having a small for gestational age infant for weight, length, and head circumference. After adjusting for confounders, the increased risks for being small for gestational age for weight or length were somewhat attenuated and no longer statistically significant; the odds ratio for microcephaly, however, was materially unchanged. In the treated women the risk of having a small for gestational age infant for weight, length, or head circumference was not statistically significantly increased. Untreated women had an increased risk of having a symmetrically small for gestational age infant for both weight and length, but the estimate was attenuated and became imprecise after adjusting for confounding. The increased risk in the treated women was non-significant.

\section{Large for gestational age}

Women with bipolar disorder were at an increased risk of having a large for gestational age infant for weight, although this was not statistically significant (table 3). Untreated women had a non-significantly increased risk of having a large for gestational age infant for head circumference, and treated women were at a non-significantly increased risk of having a large for gestational age infant for length.

\section{Congenital malformations}

The prevalence of congenital malformations was $2.0 \%(n=6517)$ in infants born to women without bipolar disorder, $1.9 \%(\mathrm{n}=11)$ in untreated women, and ranging from $0 \%$ to $3.5 \%$ in treated women (table $4 \Downarrow$ ).

\section{Variance analyses}

In the analyses assessing variation in outcome between the three groups, preterm birth, instrumental delivery, cesarean delivery, and non-spontaneous start of delivery were statistically significant (tables 2 and 3).

\section{Discussion}

Women with bipolar disorder, regardless of treatment with mood stabilisers, were at an increased risk of adverse pregnancy outcomes such as delivering a preterm infant. Moreover, infants of women with untreated bipolar disorder were at increased risk of microcephaly and neonatal hypoglycaemia.

\section{Strengths and limitations of the study}

The major strengths of our study were the large sample size with a population based cohort and the inclusion of information on maternal diagnoses, drug use, and important confounders such as smoking, body mass index, and alcohol and substance misuse. The results are highly generalisable owing to the study design and minimal losses to follow-up. The bipolar diagnoses in the Swedish patient register have high validity in relation to the diagnostic criteria of the Diagnostic and Statistical Manual of Mental Disorders, fourth edition, text revision. ${ }^{22}$ Obtaining information on drug use from the prescribed drug register ensured coverage throughout the pregnancy, except in the circumstance of admission to hospital when a drug might be administered without a prescription. However, because only four of the untreated women were admitted to a psychiatric ward during pregnancy, the lack of information on hospital drugs was of negligible importance. We did not examine other drugs or medical conditions as covariates, which, at least in theory, could have influenced our results. Treatment was measured as dispensed drugs, which does not necessarily imply the use of a drug. Regardless, fairly good agreement has been reported between the use of anticonvulsants and antipsychotics during pregnancy and dispensed drugs. ${ }^{23}$ Furthermore, misclassification of drug use is likely to be non-differential according to outcome status and, if anything, bias the risk estimates toward the null. The reasons for treatment, which were not known to us, might have biased the results, in that severe mental illness in itself, together with associated lifestyle and comorbidity factors, may be associated with adverse pregnancy and birth outcomes. The women treated with mood stabilisers during pregnancy had more admissions to psychiatric hospital than the untreated women, a finding that might reflect a more severe as well as a more active disorder. Thus, if the disorder itself was the major cause of the adverse outcomes, with a clear trend of increasing risks by severity of the condition, the most abnormal findings would be expected to be among the treated women, which was not the case. On the other hand, if the mothers treated for bipolar disorder had better monitoring and access to medical services throughout pregnancy, abnormal fetal growth might have been identified earlier and thus reduced the risk of an infant being small for gestational age. The treated group was smaller than the untreated group and accordingly the estimates were less precise for the treated women, which should be acknowledged when interpreting the results.

\section{Maternal bipolar disorder, mood stabilisers, and impact on fetal growth and microcephaly}

Untreated maternal bipolar disorder was associated with an increased risk of infants being small for gestational age for weight as well as for length, although the adjusted estimates were imprecise. In addition, this association was strongest in 
symmetrically small for gestational age infants - that is, for both weight and length. The mechanisms underlying these observations are unknown, but a previous study found associations between maternal psychosocial stress during pregnancy, high serum cortisol levels, and low birth weight and short birth length. ${ }^{24}$ It could be speculated that an untreated bipolar disorder could lead to higher psychosocial stress and higher serum cortisol levels. Another possible mechanism is that bipolar disorder and the comorbidity and lifestyle associated with the disorder are risk factors for having small for gestational age infants-for example, both treated and untreated women with bipolar disorder were more often overweight, smokers, and had an alcohol or substance misuse disorder compared with women without bipolar disorder. Atypical antipsychotics have been associated with having large for gestational age infants ${ }^{5}$ and valproate has been associated with weight gain in adults. ${ }^{2}$ Bipolar disorder and related lifestyle factors have been associated with fetal growth restriction. As there was no such association among the treated women it is possible that the drugs used to treat bipolar disorder, which included both antipsychotics and valproate, might have masked growth restriction by enhancing fetal growth. Further support for this hypothesis is reflected in our finding of increased risks of having large for gestational age infants for weight and length in treated women with bipolar disorder, even if the risk estimates were imprecise. The few studies on lithium and fetal growth are equivocal..$^{25}$ One study reported increased birth weight after use of lithium, ${ }^{25}$ whereas another did not observe any increased risks of giving birth to a large for gestational age infant after lithium use during pregnancy. ${ }^{26}$ Direct comparisons between these studies and ours are difficult to make because we investigated mood stabilisers as one entity. A recent study found that maternal bipolar disorder was associated with an increased risk of infants being small for gestational age. ${ }^{14}$ This study, however, did not include information on drug use during pregnancy and therefore if a large proportion of the mothers were untreated, as in our study, the results would be consistent with ours.

We found increased risks of microcephaly in infants of untreated mothers with bipolar disorder compared with infants of mothers without bipolar disorder. This finding is supported by a study that found a tendency for small head circumference in infants of women with bipolar disorder. ${ }^{13}$ We believe that the increased risk of microcephaly is part of a general fetal growth restriction and not an isolated phenomenon. Furthermore, the small biological variation in head circumference measures makes us more confident in our findings for small for gestational age for weight than for head circumference. We observed increased risks of neonatal hypoglycaemia in infants of women with untreated bipolar disorder, which might be explained by the higher proportion of infants being small for gestational age in this group. Being small for gestational age is a known risk factor for neonatal hypoglycaemia. ${ }^{27}$

\section{Maternal bipolar disorder, mood stabilisers, and preterm birth and congenital malformations}

Lithium, antipsychotics, and maternal bipolar disorder, but not anticonvulsants, have been associated with preterm birth, but no distinction has been made between mental disorder and drug use. ${ }^{81426}{ }^{28}$ We had the opportunity to further distinguish between illness and drug effects and found evidence for increased risks of preterm birth in both untreated and treated women.

In women treated with mood stabilisers $3.4 \%$ had an infant with a congenital malformation, which was higher than the $1.9 \%$ found in the untreated women and the $2.0 \%$ in women without bipolar disorder. Divergent results have been reported for malformations after treatment with mood stabilisers. ${ }^{79} 1025$ Some studies found an increased risk of congenital malformations, mainly heart malformations, after use of lithium, ${ }^{10}$ whereas others reported no such effects. ${ }^{79}{ }^{25}$ However, all studies on lithium use were compromised by insufficient statistical power. Furthermore, a recent study of anticonvulsants mainly included women with epilepsy. ${ }^{11}$ Doses of anticonvulsants that are used to treat epilepsy are higher than the doses used for bipolar disorder. In addition, epilepsy may be associated with increased risk of malformations and therefore results reported from studies on drug use in connection with epilepsy might not apply to women with bipolar disorder.

\section{Fertility in women with bipolar disorder}

Fertility is reduced in women with bipolar disorder. The incidence rate ratio for first child fertility was 0.36 in women with bipolar disorder in a recent Danish study. ${ }^{29}$ In our study, $0.26 \%$ of all births occurred in women with bipolar disorder. Comparable population based studies are few, but in a recent study from Taiwan the prevalence of women with bipolar disorder giving birth was only $0.06 \%{ }^{14}$

\section{Conclusion}

Decision making in treatment of bipolar disorder involves balancing risks. ${ }^{28}$ On the one hand there is the increased risk of mothers relapsing with mood episodes and on the other there is the risk of potential congenital malformations and perinatal complications after exposure of the fetus to drugs. ${ }^{30-32}$ Our findings of increased risks for several of the investigated outcomes also in the untreated women suggest that mood stabilising treatment is probably not the sole reason for the increased risk of adverse pregnancy and birth outcomes previously observed in women with bipolar disorder. The role of treatment is, however, still unclear as the overall analyses of variation in outcomes generally did not support a significant difference between treated and untreated women. The possibility of an anabolic drug effect with increased risks of gestational diabetes and reduced risks of fetal growth restriction should be noted.

Contributors: RB conceived the study. LB carried out the statistical analyses. RB and HK wrote the first draft of the manuscript. All authors contributed to the study design, critically reviewed the manuscript, and approved the final version for submission. All authors had full access to all of the data (including statistical reports and tables) in the study and can take responsibility for the integrity of the data and the accuracy of the data analysis. RB is the guarantor

Funding: This study was funded by unrestricted grants from Lennanders Foundation, Gillbergska Foundation, Uppsala County Council (ALF-grants), and by the authors' affiliations.

Competing interests: All authors have completed the ICMJE uniform disclosure form at www.icmje.org/coi_disclosure.pdf (available on request from the corresponding author) and declare: no support from any organisation for the submitted work; no financial relationships with any organisations that might have an interest in the submitted work in the previous three years; and no other relationships or activities that could appear to have influenced the submitted work.

Ethical approval: This study was approved by the regional ethics board at the Faculty of Medicine, Uppsala University (Dnr: 2008/305).

Data sharing: No additional data available.

Müller-Oerlinghausen B, Berghöfer A, Bauer M. Bipolar disorder. Lancet 2002;359:241-7. Yatham LN, Kennedy SH, Schaffer A, Parikh SV, Beaulieu S, O'Donovan C, et al. Canadian Network for Mood and Anxiety Treatments (CANMAT) and International Society for Bipolar 


\section{What is already known on this topic}

Mood stabilising drugs have been associated with adverse pregnancy outcomes

Knowledge on the risks of adverse pregnancy outcomes in bipolar disorder and the role of treatment is limited

\section{What this study adds}

Infants of women with bipolar disorder had increased risks of preterm birth, irrespective of whether the mother had received mood stabilising drugs

Infants of women with untreated bipolar disorder had also increased risks of microcephaly and neonatal hypoglycaemia

Disorders (ISBD) collaborative update of CANMAT guidelines for the management of patients with bipolar disorder: update 2009. Bipolar Disord 2009;11:225-55.

3 Yonkers KA, Wisner KL, Stowe Z, Leibenluft E, Cohen L, Miller L, et al. Management of bipolar disorder during pregnancy and the postpartum period. Am J Psychiatry 2004; $161: 608-20$

4 Lin HC, Chen IJ, Chen YH, Lee HC, Wu FJ. Maternal schizophrenia and pregnancy outcome: does the use of antipsychotics make a difference? Schizophr Res 2010;116:55-60.

5 Newham JJ, Thomas SH, MacRitchie K, McElhatton PR, McAllister-Williams RH. Birth weight of infants after maternal exposure to typical and atypical antipsychotics: prospective comparison study. Br J Psychiatry 2008;192:333-7.

6 Newport DJ, Calamaras MR, DeVane CL, Donovan J, Beach AJ, Winn S, et al. Atypical antipsychotic administration during late pregnancy: placental passage and obstetrical outcomes. Am J Psychiatry 2007;164:1214-20.

7 Reis M, Kallen B. Maternal use of antipsychotics in early pregnancy and delivery outcome. $J$ Clin Psychopharmacol 2008;28:279-88.

8 Boden R, Lundgren M, Brandt L, Reutfors J, Kieler H. Antipsychotics during pregnancy: relation to fetal and maternal metabolic effects. Arch Gen Psychiatry 2012:69:715-21.

9 Cohen LS, Friedman JM, Jefferson JW, Johnson EM, Weiner ML. A reevaluation of risk of in utero exposure to lithium. JAMA 1994;271:146-50.

10 Kallen B, Tandberg A. Lithium and pregnancy. A cohort study on manic-depressive women. Acta Psychiatr Scand 1983;68:134-9.

11 Tomson T, Battino D, Bonizzoni E, Craig J, Lindhout D, Sabers A, et al. Dose-dependent risk of malformations with antiepileptic drugs: an analysis of data from the EURAP epilepsy and pregnancy registry. Lancet Neurol 2011;10:609-17.

12 Schou M. Treating recurrent affective disorders during and after pregnancy. What can be taken safely? Drug Saf 1998;18:143-52.

13 Jablensky AV, Morgan V, Zubrick SR, Bower C, Yellachich LA. Pregnancy, delivery, and neonatal complications in a population cohort of women with schizophrenia and major affective disorders. Am J Psychiatry 2005;162:79-91.

14 Lee H-C, Lin H-C. Maternal bipolar disorder increased low birthweight and preterm births: a nationwide population-based study. J Affect Disord 2010;121:100-5.

15 Ludvigsson JF, Otterblad-Olausson P, Pettersson BU, Ekbom A. The Swedish personal identity number: possibilities and pitfalls in healthcare and medical research. Eur $J$ Epidemiol 2009;24:659-67.

16 Wettermark B, Hammar N, Fored C, Leimanis A, Otterblad Olausson P, Bergman U, et al. The new Swedish Prescribed Drug Register-opportunities for pharmacoepidemiological research and experience from the first six months. Pharmacoepidemiol Drug Saf 2007:16:726-35.

17 Cnattingius S, Ericson A, Gunnarskog J, Kallen B. A quality study of a medical birth registry. Scand J Soc Med 1990;18:143-8.

18 Darj E, Lindmark G. [Not all women use maternal health services. Language barriers and fear of the examination are common]. Läkartidningen 2002;99:41-4.

19 Høgberg U, Larsson N. Early dating by ultrasound and perinatal outcome. Acta Obstet et Gynecol Scand 1997;76:907-12.
20 Marsal K, Persson PH, Larsen T, Lilia H, Selbing A, Sultan B. Intrauterine growth curves based on ultrasonically estimated foetal weights. Acta Paediatr 1996;85:843-8.

21 Niklasson A, Ericson A, Fryer JG, Karlberg J, Lawrence C, Karlberg P. An update of the Swedish reference standards for weight, length and head circumference at birth for given gestational age (1977-1981). Acta Paediatr Scand 1991;80:756-62.

22 Sellgren C, Landen M, Lichtenstein P, Hultman CM, Langstrom N. Validity of bipolar disorder hospital discharge diagnoses: file review and multiple register linkage in Sweden. Acta Psychiatr Scand 2011;124:447-53.

23 Stephansson O, Granath F, Svensson T, Haglund B, Ekbom A, Kieler H. Drug use during pregnancy in Sweden-assessed by the Prescribed Drug Register and the Medical Birth Register. Clin Epidemiol 2011;3:43-50.

24 Bolten MI, Wurmser H, Buske-Kirschbaum A, Papousek M, Pirke KM, Hellhammer D. Cortisol levels in pregnancy as a psychobiological predictor for birth weight. Arch Womens Ment Health 2011:14:33-41.

25 Jacobson SJ, Jones K, Johnson K, Ceolin L, Kaur P, Sahn D, et al. Prospective multicentre study of pregnancy outcome after lithium exposure during first trimester. Lancet 1992;339:530-3.

26 Troyer WA, Pereira GR, Lannon RA, Belik J, Yoder MC. Association of maternal lithium exposure and premature delivery. $J$ Perinatol 1993:13:123-7.

27 Meji A, Dorval VG, Nuyt AM, Carceller A. Hypoglycemia in term newborns with a birth weight below the 10th percentile. Paediatr Child Health 2010;15:271-5.

28 Galbally M, Roberts M, Buist A. Mood stabilizers in pregnancy: a systematic review. Aus N Z J Psychiatry 2010;44:967-77.

29 Laursen TM, Munk-Olsen T. Reproductive patterns in psychotic patients. Schizophr Res 2010;121:234-40.

30 Viguera AC, Whitfield T, Baldessarini RJ, Newport DJ, Stowe Z, Reminick A, et al. Risk of recurrence in women with bipolar disorder during pregnancy: prospective study of mood stabilizer discontinuation. Am J Psychiatry 2007;164:1817-24; quiz 923.

31 Gentile S. Prophylactic treatment of bipolar disorder in pregnancy and breastfeeding: focus on emerging mood stabilizers. Bipolar Disord 2006;8:207-20.

32 Newport DJ, Viguera AC, Beach AJ, Ritchie JC, Cohen LS, Stowe ZN. lithium placental passage and obstetrical outcome: implications for clinical management during late pregnancy. Am J Psychiatry 2005;162:2162-70.

\section{Accepted: 15 October 2012}

\section{Cite this as: BMJ 2012;345:e7085}

This is an open-access article distributed under the terms of the Creative Commons Attribution Non-commercial License, which permits use, distribution, and reproduction in any medium, provided the original work is properly cited, the use is non commercial and is otherwise in compliance with the license. See: http://creativecommons.org/licenses/by$\mathrm{nc} / 2.0 /$ and http://creativecommons.org/licenses/by-nc/2.0/legalcode. 


\section{Tables}

\section{Table 1| Maternal personal and clinical characteristics}

Bipolar disorder

Characteristics

No bipolar disorder ( $n=331263)$ No mood stabilisers $(n=554)$ Mood stabilisers ${ }^{*}(n=320)$

Maternal country of birth:

\begin{tabular}{|c|c|c|c|}
\hline Sweden & $259956(78.5)$ & $482(87.0)$ & $277(86.6)$ \\
\hline Other Nordic countries & 66037 (19.9) & $59(10.6)$ & $37(11.6)$ \\
\hline Non-Nordic countries & $5270(1.6)$ & $13(2.3)$ & $6(1.9)$ \\
\hline \multicolumn{4}{|l|}{ Maternal age at delivery: } \\
\hline$<25$ years & $48336(14.6)$ & $93(16.8)$ & $59(18.4)$ \\
\hline $25-34$ years & $211660(63.9)$ & $324(58.5)$ & $193(60.3)$ \\
\hline$\geq 35$ years & $71267(21.5)$ & $137(24.7)$ & $68(21.3)$ \\
\hline \multicolumn{4}{|l|}{ Birth order: } \\
\hline 1 & $149207(45.0)$ & $260(46.9)$ & $172(53.8)$ \\
\hline $2-3$ & $163692(49.4)$ & $260(46.9)$ & $129(40.3)$ \\
\hline$\geq 4$ & $18364(5.5)$ & $34(6.1)$ & $19(5.9)$ \\
\hline \multicolumn{4}{|l|}{ Maternal cohabitation: } \\
\hline With father of child & $312737(94.4)$ & $483(87.2)$ & $267(83.4)$ \\
\hline Single & $5651(1.7)$ & $29(5.2)$ & $23(7.2)$ \\
\hline Other & $12875(3.9)$ & $42(7.6)$ & $30(9.4)$ \\
\hline \multicolumn{4}{|l|}{ Maternal smoking in early pregnancy: } \\
\hline No & $308233(93.0)$ & $444(80.1)$ & $251(78.4)$ \\
\hline$<10$ & $17765(5.4)$ & $76(13.7)$ & $42(13.1)$ \\
\hline$\geq 10$ & $5265(1.6)$ & $34(6.1)$ & $27(8.4)$ \\
\hline \multicolumn{4}{|l|}{ Maternal body mass index in early pregnancy: } \\
\hline$<18.5$ & $7706(2.3)$ & $11(2.0)$ & $2(0.6)$ \\
\hline $18.5-24.9$ & $195804(59.1)$ & $271(48.9)$ & $148(46.3)$ \\
\hline $25.0-29.9$ & $78639(23.7)$ & $155(28.0)$ & $83(25.9)$ \\
\hline$\geq 30.0$ & $37330(11.3)$ & $92(16.6)$ & $66(20.6)$ \\
\hline Ever admitted to psychiatric hospital before pregnancy & $8339(2.5)$ & $266(48.0)$ & $216(67.5)$ \\
\hline \multicolumn{4}{|l|}{ Time since most recent admission to psychiatric hospital : } \\
\hline$<1$ year & $298(3.6)$ & $26(9.8)$ & $68(31.5)$ \\
\hline $1-2$ years & $1479(17.7)$ & $68(25.6)$ & $65(30.1)$ \\
\hline$>2$ years & $6562(78.7)$ & $172(64.7)$ & $83(38.4)$ \\
\hline Admitted to psychiatric hospital during present pregnancy & $191(0.1)$ & $4(0.7)$ & $8(2.5)$ \\
\hline Diagnosis of substance misuse disordert: & $5793(1.7)$ & $93(17.0)$ & $66(20.1)$ \\
\hline Alcohol misuse & $4087(1.2)$ & $57(10.3)$ & $41(12.8)$ \\
\hline Other substance misuse & $2522(0.8)$ & $60(10.8)$ & $47(14.7)$ \\
\hline
\end{tabular}

*Lithium, antipsychotics, carbamazepine, lamotrigine, or valproate.

†Inpatient or outpatient diagnoses since 1997 with ICD-10 codes F10-F19. 


\begin{tabular}{|c|c|c|c|c|c|}
\hline \multirow[b]{2}{*}{ Variables } & \multirow[b]{2}{*}{ Total No } & \multirow[b]{2}{*}{ No (\%) with outcome } & \multicolumn{2}{|c|}{ Odds ratio $(95 \% \mathrm{Cl})$} & \multirow[b]{2}{*}{$P$ value } \\
\hline & & & Unadjusted & Adjusted* & \\
\hline \multicolumn{6}{|l|}{ Gestational diabetes: } \\
\hline No bipolar disorder & 331263 & $5536(1.7)$ & 1 (reference) & 1 (reference) & \multirow[t]{3}{*}{0.96} \\
\hline Untreated bipolar disorder & 554 & $10(1.8)$ & 1.06 (0.56 to 2.02$)$ & $1.01(0.53$ to 1.94$)$ & \\
\hline Treated bipolar disorder† & 320 & $6(1.9)$ & $1.18(0.55$ to 2.56$)$ & $1.12(0.52$ to 2.43$)$ & \\
\hline \multicolumn{6}{|l|}{ Instrumental deliverył: } \\
\hline No bipolar disorder & 331263 & $81730(24.7)$ & 1 (reference) & 1 (reference) & \multirow[t]{3}{*}{$<0.001$} \\
\hline Untreated bipolar disorder & 554 & $183(33.0)$ & $1.52(1.27$ to 1.82$)$ & $1.49(1.24$ to 1.81$)$ & \\
\hline Treated bipolar disorder† & 320 & $109(34.1)$ & $1.52(1.20$ to 1.92$)$ & 1.39 (1.09 to 1.79$)$ & \\
\hline \multicolumn{6}{|l|}{ Caesarean delivery: } \\
\hline No bipolar disorder & 331263 & $55692(16.8)$ & 1 (reference) & 1 (reference) & \multirow[t]{3}{*}{$<0.001$} \\
\hline Untreated bipolar disorder & 554 & $130(23.5)$ & $1.52(1.25$ to 1.85$)$ & 1.45 (1.18 to 1.78$)$ & \\
\hline Treated bipolar disorder† & 320 & $82(25.6)$ & 1.69 (1.32 to 2.16$)$ & 1.56 (1.20 to 2.03$)$ & \\
\hline \multicolumn{6}{|c|}{ Non-spontaneous start of delivery: } \\
\hline No bipolar disorder & 331263 & $68533(20.7)$ & 1 (reference) & 1 (reference) & \multirow[t]{3}{*}{$<0.001$} \\
\hline Untreated bipolar disorder & 554 & $171(30.9)$ & 1.69 (1.4 to 2.03$)$ & 1.57 (1.30 to 1.90$)$ & \\
\hline Treated bipolar disorder† & 320 & $120(37.5)$ & 2.28 (1.82 to 2.87$)$ & 2.12 (1.68 to 2.67$)$ & \\
\hline \multicolumn{6}{|c|}{ Preterm birth, <37 weeks' gestation: } \\
\hline No bipolar disorder & 331263 & $15785(4.8)$ & 1 (reference) & 1 (reference) & \multirow[t]{3}{*}{0.03} \\
\hline Untreated bipolar disorder & 554 & $42(7.6)$ & $1.64(1.20$ to 2.24$)$ & 1.48 (1.08 to 2.03$)$ & \\
\hline Treated bipolar disorder† & 320 & $26(8.1)$ & 1.75 (1.18 to 2.62$)$ & $1.50(1.01$ to 2.24$)$ & \\
\hline \multicolumn{6}{|l|}{ Apgar score < $>$ at 5 min§: } \\
\hline No bipolar disorder & 331263 & $3541(1.1)$ & 1 (reference) & 1 (reference) & \multirow[t]{3}{*}{0.48} \\
\hline Untreated bipolar disorder & 554 & $11(2.0)$ & $1.87(1.03$ to 3.4$)$ & 1.56 (0.85 to 2.86$)$ & \\
\hline Treated bipolar disorder† & 320 & $4(1.3)$ & $1.17(0.44$ to 3.13$)$ & 0.88 (0.33 to 2.34$)$ & \\
\hline \multicolumn{6}{|l|}{ Neonatal hypoglycaemia: } \\
\hline No bipolar disorder & 331263 & $8302(2.5)$ & 1 (reference) & 1 (reference) & \multirow[t]{3}{*}{0.19} \\
\hline Untreated bipolar disorder & 554 & $24(4.3)$ & 1.76 (1.15 to 2.68$)$ & 1.51 (1.04 to 2.43 ) & \\
\hline Treated bipolar disorder $\dagger$ & 320 & $11(3.4)$ & $1.38(0.75$ to 2.52$)$ & $1.18(0.64$ to 2.16$)$ & \\
\hline
\end{tabular}

*Adjusted for birth order and for maternal age, cohabitation, smoking, height, and diagnosis of alcohol or substance misuse disorder. †Filling a prescription for lithium, antipsychotics, carbamazepine, lamotrigine, or valproate during pregnancy. łIncludes caesarean delivery, forceps, and ventouse.

$\S$ Adjusted for caesarean delivery, preterm birth, and remaining covariates in table. 
Table 3 | Odds of being small or large for gestational age associated with maternal bipolar disorder and treatment with mood stabilisers during pregnancy compared with reference group of infants of mothers without bipolar disorder and not using mood stabilisers during pregnancy

\begin{tabular}{|c|c|c|c|c|c|c|c|c|c|c|}
\hline \multirow[t]{2}{*}{ Variables } & \multirow[t]{2}{*}{ No } & \multicolumn{5}{|c|}{ Small for gestational age ${ }^{*}$} & \multicolumn{4}{|c|}{ Large for gestational age ${ }^{*}$} \\
\hline & & & $\%$ & $\begin{array}{c}\text { Univariate } \\
\text { odds ratio } \\
(95 \% \mathrm{Cl})\end{array}$ & $\begin{array}{c}\text { Multivariate } f \\
\text { odds ratio }(95 \% \\
\text { Cl) }\end{array}$ & $\begin{array}{c}\mathbf{P} \\
\text { value§ }\end{array}$ & $\%$ & $\begin{array}{c}\text { Univariate } \\
\text { odds ratio } \\
(95 \% \mathrm{Cl})\end{array}$ & $\begin{array}{c}\text { Multivariate† } \\
\text { odds ratio } \\
(95 \% \mathrm{Cl})\end{array}$ & $\begin{array}{c}P \\
\text { value§ }\end{array}$ \\
\hline \multicolumn{11}{|l|}{ Birth weight: } \\
\hline No bipolar disorder & 330231 & & 2.3 & 1 (reference) & 1 (reference) & \multirow[t]{3}{*}{0.46} & 2.3 & 1 (reference) & 1 (reference) & \multirow[t]{3}{*}{0.25} \\
\hline $\begin{array}{l}\text { Untreated bipolar } \\
\text { disorder }\end{array}$ & 551 & & 3.4 & $\begin{array}{c}1.59(1.01 \text { to } \\
2.51)\end{array}$ & $\begin{array}{c}1.41(0.88 \text { to } \\
2.24)\end{array}$ & & 3.3 & $\begin{array}{c}1.37(0.86 \text { to } \\
2.19)\end{array}$ & $\begin{array}{c}1.43(0.89 \text { to } \\
2.30)\end{array}$ & \\
\hline $\begin{array}{l}\text { Treated bipolar } \\
\text { disorder }\end{array}$ & 319 & & 2.5 & $\begin{array}{c}1.14(0.57 \text { to } \\
2.29)\end{array}$ & $\begin{array}{c}0.93(0.46 \text { to } \\
1.88)\end{array}$ & & 3.1 & $\begin{array}{l}1.30(0.70 \text { to } \\
2.41)\end{array}$ & $\begin{array}{c}1.54(0.83 \text { to } \\
2.87)\end{array}$ & \\
\hline \multicolumn{11}{|l|}{ Birth length: } \\
\hline No bipolar disorder & 328147 & & 2.3 & 1 (reference) & 1 (reference) & \multirow[t]{3}{*}{0.29} & 2.3 & 1 (reference) & 1 (reference) & \multirow[t]{3}{*}{0.40} \\
\hline $\begin{array}{l}\text { Untreated bipolar } \\
\text { disorder }\end{array}$ & 550 & & 3.8 & $\begin{array}{c}1.75(1.13 \text { to } \\
2.71)\end{array}$ & $\begin{array}{c}1.51(0.97 \text { to } \\
2.34)\end{array}$ & & 1.6 & $\begin{array}{c}0.71(0.37 \text { to } \\
1.36)\end{array}$ & $\begin{array}{c}0.75(0.39 \text { to } \\
1.45)\end{array}$ & \\
\hline $\begin{array}{l}\text { Treated bipolar } \\
\text { disorder } \ddagger\end{array}$ & 314 & & 3.2 & $\begin{array}{c}1.43(0.77 \text { to } \\
2.67)\end{array}$ & $\begin{array}{c}1.15(0.61 \text { to } \\
2.15)\end{array}$ & & 2.9 & $\begin{array}{c}1.25(0.65 \text { to } \\
2.40)\end{array}$ & $\begin{array}{c}1.44(0.75 \text { to } \\
2.77)\end{array}$ & \\
\hline \multicolumn{11}{|l|}{ Head circumference: } \\
\hline No bipolar disorder & 324844 & 2.3 & & 1 (reference) & 1 (reference) & \multirow[t]{3}{*}{0.16} & 2.3 & 1 (reference) & 1 (reference) & \multirow[t]{3}{*}{0.70} \\
\hline $\begin{array}{l}\text { Untreated bipolar } \\
\text { disorder }\end{array}$ & 542 & 3.9 & & 1.77 (1.14 to 2.73$)$ & $\begin{array}{c}1.68(1.07 \text { to } \\
2.62)\end{array}$ & & 3.0 & $\begin{array}{c}1.25(0.76 \text { to } \\
2.06)\end{array}$ & $\begin{array}{c}1.27(0.77 \text { to } \\
2.10)\end{array}$ & \\
\hline $\begin{array}{l}\text { Treated bipolar } \\
\text { disorder } \ddagger\end{array}$ & 311 & 3.3 & & 1.45 (0.78 to 2.71$)$ & $\begin{array}{c}1.26(0.67 \text { to } \\
2.37)\end{array}$ & & 2.3 & $\begin{array}{c}0.90(0.39 \text { to } \\
2.07)\end{array}$ & $\begin{array}{c}0.97(0.42 \text { to } \\
2.23)\end{array}$ & \\
\hline \multicolumn{11}{|l|}{$\begin{array}{l}\text { Low birth weight and } \\
\text { short length: }\end{array}$} \\
\hline No bipolar disorder & 327590 & 0.8 & & 1 (reference) & 1 (reference) & \multirow[t]{3}{*}{0.35} & - & - & - & \\
\hline $\begin{array}{l}\text { Untreated bipolar } \\
\text { disorder }\end{array}$ & 547 & 1.8 & & 2.24 (1.20 to 4.19$)$ & $\begin{array}{c}1.84(0.97 \text { to } \\
3.53)\end{array}$ & & - & - & - & \\
\hline $\begin{array}{l}\text { Treated bipolar } \\
\text { disorder } \ddagger\end{array}$ & 314 & 1.3 & & $1.53(0.57$ to 4.07$)$ & $\begin{array}{c}1.14(0.42 \text { to } \\
3.08)\end{array}$ & & - & - & - & \\
\hline
\end{tabular}

*Small or large for gestational age were defined as being in $\leq 2.3$ centile or $\geq 97.7$ centile ( 2 standard deviations), respectively, of total population in cohort. Growth references for this calculation were from Marsal et al $1996^{20}$ for birth weight and from Nicklasson et al $1991^{21}$ for birth length and head circumference. †Adjusted for birth order and for maternal age, country of birth, cohabitation, smoking, height, and diagnosis of alcohol or substance misuse disorder. ‡Filling a prescription with lithium, antipsychotics, carbamazepine, lamotrigine, or valproate during pregnancy.

$\S \mathrm{P}$ value for overall analysis of variation in outcome between three exposure groups. 
Table 4| Frequency of congenital malformations in women with bipolar disorder treated with mood stabilising drugs during early pregnancy

\begin{tabular}{lcccc} 
Mood stabilisers & No in group & No (\%) with outcome & P value* & Congenital malformations \\
Lamotrigine & 116 & $4(3.5)$ & 0.12 & 2 talipes equinovarus,+ 2 heart malformations \\
\hline Antipsychotics & 113 & $4(3.5)$ & 0.11 & $\begin{array}{l}1 \text { talipes equinovarus }+, 1 \text { cleft palate, } 1 \text { urinary } \\
\text { system agenesis, } 1 \text { heart malformation } \ddagger\end{array}$ \\
\hline Lithium & 107 & $3(2.8)$ & 0.19 & 2 heart malformations $\neq, 1$ hypospadias \\
\hline Valproate & 32 & $1(3.1)$ & 0.34 & 1 hypospadias \\
\hline Carbamazepine & 7 & $0(0.0)$ & - & -
\end{tabular}

*Fisher's exact test. P value for difference in proportions between women with treated bipolar disorder and women without bipolar disorder. †Used lamotrigine and antipsychotics.

fUsed antipsychotics and lithium. 


\section{Figure}

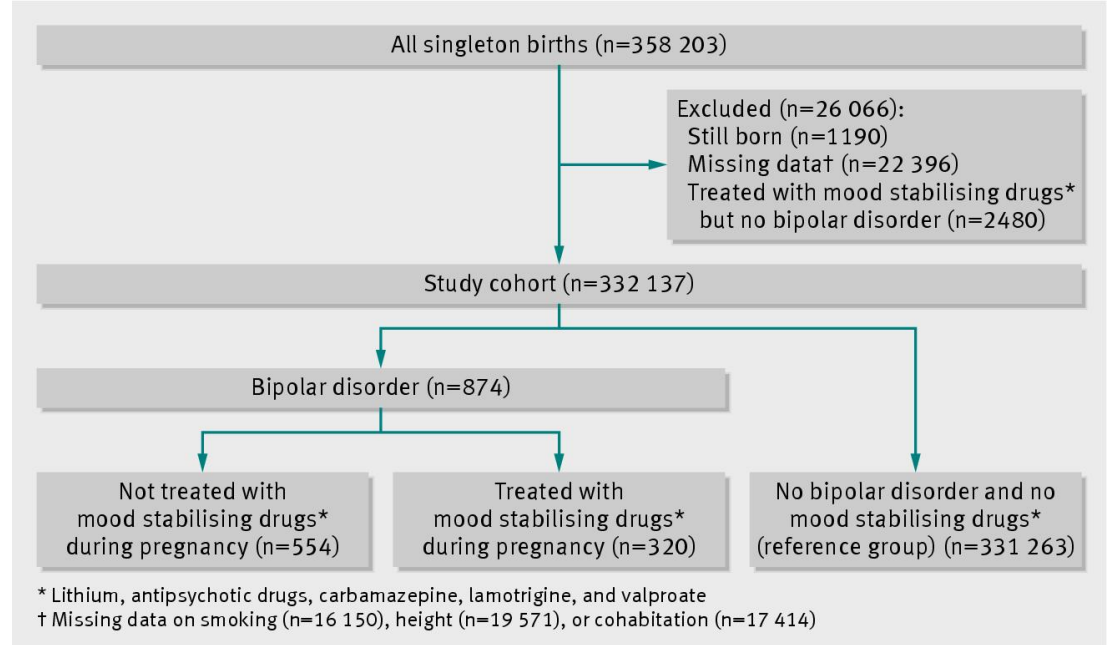

Flow of women through study 